\section{Affordable disinfection made easy}

Are you looking for a surface cleaner that effectively cleans even the toughest to reach spots of your practice?

AIRGENE CE Airborne Surface Disinfectant from Eschmann is a smart way to help guarantee that indoor surfaces are properly disinfected. The unique one-shot technology forms a cloud of the product that covers an area of $40 \mathrm{~m}^{3}$ in under one hour, destroying $99.99 \%$ of bacteria and viruses, including Coronavirus, and neutralising odours caused by the decomposition of surface bacteria.

\section{AIRGENE CE}

Airborne Surface Disinfectant is available to purchase on the Eschmann website as a single unit and in cases of twelve.

For more information on the highly effective and affordable range of infection control products from Eschmann, visit www. eschmann.co.uk or call 01903875787.

\title{
The treatment centre that enhances the dental experience
}

Created with well-being in mind, Heka's UNIC range of dental treatment centres combines aesthetics with functionality, creating the perfect environment for a pleasant visit to the dentist.

To offer a quick snapshot of what UNIC can offer, the instrument table's handle is fully integrated with UNIC's display and touch pads. It is easy to find by both eye and hand - even when your attention is elsewhere. With a light touch on the cuspidor touch pad, the suction stops, the operating light goes off and the patient's chair adjusts to the rinsing position. Meanwhile, the glass fills with water. By touching the cuspidor touch pad again, the patient's chair returns to its previous working position.

Intrigued? Who wouldn't be?

If you would like to know more, visit https://bit.ly/3apfsAF, email info@ quintessdenta.com or call 0286862 8966 (UK) or 04868628966 (ROI).

\section{Providing professional support}

Treating patients with complex endodontic needs isn't easy. So, why not let us lend a helping hand and refer them to EndoCare?

Our team of endodontic specialists have years of experience treating complex cases and have saved thousands of teeth that would have otherwise needed extraction.

Using only cutting-edge treatments and techniques, we can guarantee your patient treatment that is as pain-free as possible, meaning we're also a great choice for patients who are usually difficult to treat due to fear.

When we return your patient to your care we always provide comprehensive treatment notes and our suggested next steps.

We're here to help you, so if you want to find out more about the referral process, contact the team on 02072240999 or visit www.endocare.co.uk.
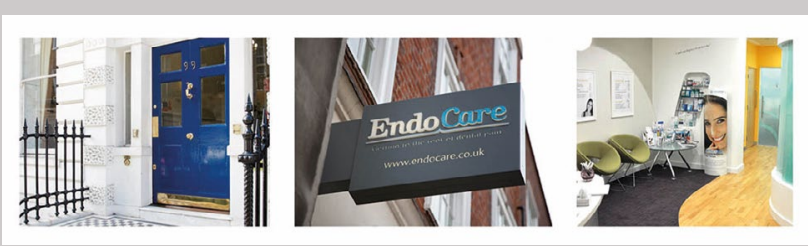

\section{Infection control has never been more important}

For the first time ever, the science of ultrasonics can now be used in hospitals and pharmaceuticals to help reduce airborne contagion spread, and maintain critical sterilisation, via the Portascanner COVID-19 by Coltraco Ultrasonics. Maintenance of our rooms/wards has never been more pressing, as a December 2020 study showed that $56 \%$ of air samples taken from hospital hallways contain high levels of coronavirus. ${ }^{1}$

Existing methods for achieving pressurisation are disruptive - requiring patients to be moved, costly - bringing in third-party contractors, and ineffective - user cannot identify specific areas of leakage, leaving remedial action to inaccurate speculation. Whilst 2020 hit the pause button, innovation thrived. Coltraco Ultrasonics applied 30 years of expertise to design a solution to help the NHS fight COVID-19 which resulted in winning a UK-Government funded Emergency Response Grant. Seven months later, Coltraco Ultrasonics proudly present a solution to improve air quality and protect staff and patients against the spread of airborne diseases, such as SARS-CoV-2 and beyond.

Portascanner COVID-19 is a non-invasive answer to 'patch and hope' measures. With minimal training this maintenance equipment allows the user to efficiently locate and then quantify the leaks, as small as $0.5 \mathrm{~mm}$ in diameter. The air flow rate can then be calculated, generating an air permeability value for an entire cleanroom or hospital ward. The healthcare sector can now go above and beyond standards, with the ability to photograph, record, and export test reports, all in the tap of a finger. Maintaining pressurisation for the control of infectious diseases, and sterilisation for hazardous drugs has never been more pertinent. Portascanner COVID-19 provides a handheld solution that gives you confidence in the security of your room or ward, and the safety of its people.

For further information contact sales@ coltraco.co.uk, call 02076298475 or visit www.coltraco.co.uk.

Reference

1. Birgand G, Peiffer-Smadja N, Fournier S, Kerneis S, Lescure F, Lucet J. Assessment of Air Contamination by SARS-CoV-2 in Hospital Settings. JAMA Netw Open 2020; 3: e2033232. 